\title{
Mathematical modelling of creep/environment interactions
}

\section{B F DYSON* and S OSGERBY}

Division of Materials Metrology, National Physical Laboratory, Teddington, TW11 0LW, UK

* Present address: Department of Materials, Imperial College of Science, Technology and Medicine, London SW7 2BP, UK

\begin{abstract}
Physically-based creep Continuum Damage Mechanics (CDM) is briefly reviewed to introduce the formalism necessary for mathematical modelling of creep and fracture in the presence of a chemically-interacting fluid environment. A recently developed theory of creep in precipitationhardened alloys is presented in the form of a constitutive equation and two important creep/environment interactions are discussed in detail. Spallation of oxide scales during creep of a low-alloy ferritic steel is one and is modelled using the new creep constitutive equation which incorporates particle-ageing as the principal intrinsic damage mechanism. Lack of experimental data has meant that only qualitative support for the model predictions could be given. Carbon dioxide gas bubble formation along grain boundaries in nickel alloys is the other form of environmental attack considered; a new kinetic model based upon oxyen diffusion-control is described and shown to be in quantitative agreement with a large experimental dataset.
\end{abstract}

Keywords. Continuum damage mechanics; creep modelling; reactionfront kinetics; diffusion; degradation; damage; gas bubble formation.

\section{Introduction}

Mechanical test data for creep design are mainly procured in a laboratory air environment, whereas materials entering service in component form are often exposed to oxidising, sulphidising or carburising atmospheres. The potential for material degradation (or 'damage') in these environments is an unwelcome irritant to those concerned with predicting long-term component performance in service using data from short-term laboratory tests. However, environmentally-induced degradation of a material is only one of many mechanisms that can adversely affect a component's creep lifetime and its quantification cannot therefore be considered in isolation: the

A list of symbols is given at the end of the paper 
state of stress experienced by a component or its fabrication route are two wellresearched areas that can also reduce lifetimes to well below those predicted simply on the basis of uniaxial data. For example, material in bent pipework can be made much less ductile (with a consequent reduction in lifetime relative to virgin material) because of plastic strain-induced grain boundary cavitation; similarly, low ductility fractures are induced by a combination of local changes of microstructure and triaxial stresses created during welding. Predictive modelling of creep/environment interactions must therefore be within an overall life prediction framework.

The present paper first presents a brief state-of-the-art review of physically-based creep Continuum Damage Mechanics (CDM). This mechanics has evolved over the past decade to deal quantitatively with design and remanent life prediction in situations where a variety of material damage mechanisms can control failure. The damage equations have been incorporated individually into a new constitutive description of creep that is relevant to nickel-base superalloys, ferritic steels and aluminium alloys. A multi-damage version is then used to advance further the quantification of two important creep/environment interactions.

\section{Mechanics framework for creep lifetime prediction}

In an effort to 'build bridges' between engineers engaged in lifetime prediction and metal scientists endeavouring to understand the underlying micromechanisms of material degradation, Ashby \& Dyson (1984) proposed what has become known as physically-based creep Continuum Damage Mechanics (CDM). Four broad categories of material-damage were identified, each containing more than one micromechanism: (i) loss of external load-bearing section due to deformation at constant volume; (ii) loss of effective internal load-bearing section due to voiding or cracking; (iii) a progressive softening caused by degradation of the dislocation and/or particulate microstructure; (iv) a surface weakening due to chemical interaction with the environment. A nondimensional 'damage parameter', $S$, was defined for each micromechanism and its rate of evolution and interaction with strain rate $\dot{\varepsilon}$, quantified. When each micro- mechanism acted alone, the strain rate was found to be represented generally by

$$
\dot{\varepsilon}=\dot{\varepsilon}(\sigma T S),
$$

while the damage rate had one of four forms:

$$
\begin{aligned}
& \dot{S}=\dot{S}(\sigma T S), \\
& \dot{S}=\dot{S}(T S), \\
& \dot{S}=\dot{S}(\sigma T S R), \\
& \dot{S}=\dot{S}(T S R)
\end{aligned}
$$

In (1)-(5), $\sigma$ is the applied uniaxial stress; $T$ is temperature and $R$ is the radius of a cylindrical testpiece.

Only (3) - describing damage due to coarsening of particles - and (5)-describing damage due to internal oxidation - are independent of deformation rate. Equations (4) and (5) describe damage due to chemical interactions with the environment and thus depend on radius $R$ - the larger the testpiece, the smaller the interaction. 


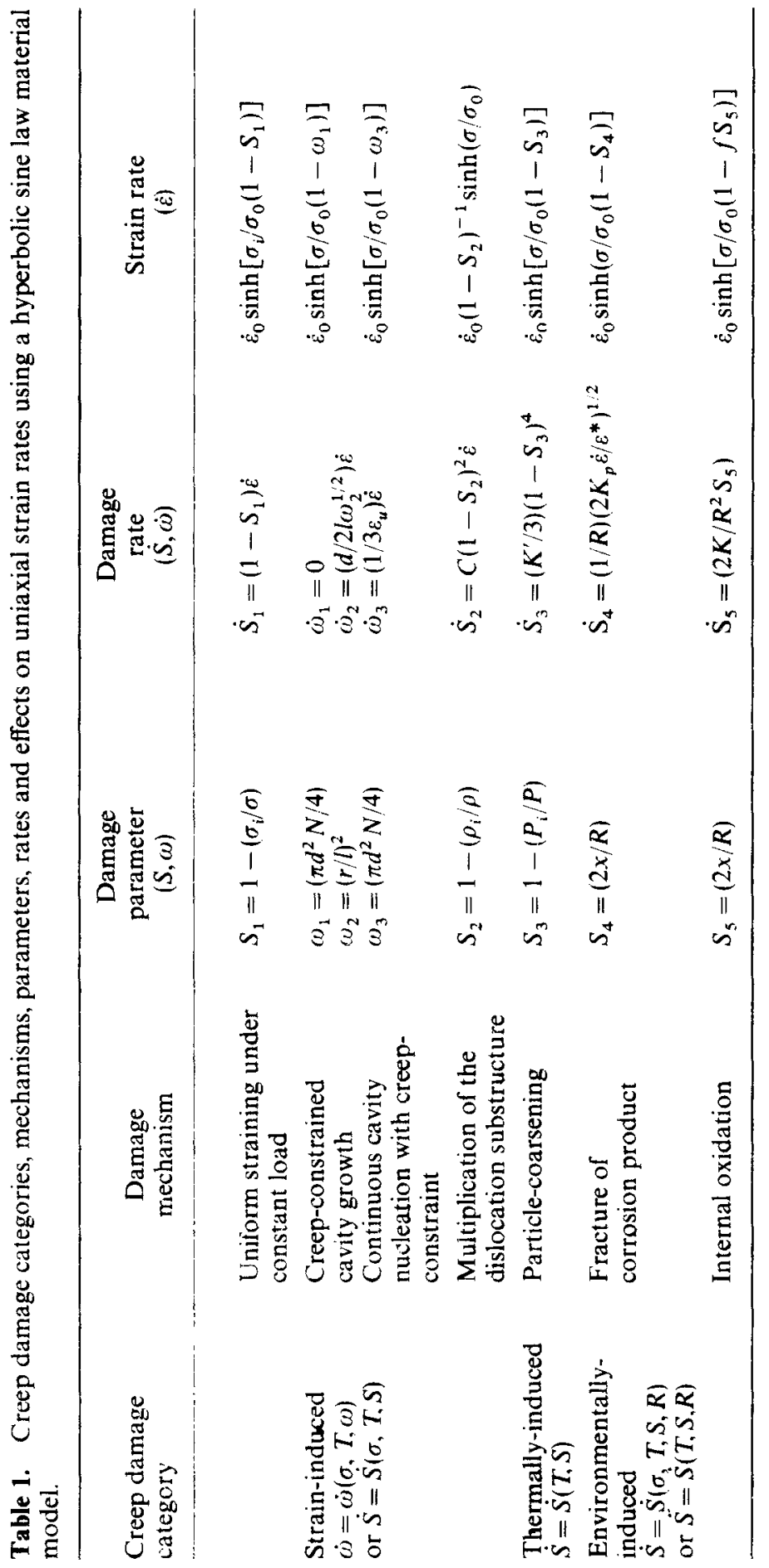


Ashby \& Dyson (1984) used a material model with a power law stress function to formulate explicit pairs of equations consisting of (1) combined with various appropriate forms of the damage equations (2) $-(5)$. Over the past decade, several developments have taken place: a recognition of the importance of a two-damage formulation for particle-strengthened engineering alloys, even under constant applied stress (Dyson \& Gibbons 1987); a multiaxial formulation for use in finite element analyses of components (Othman et al 1993); a methodology (CRISPEN) for extracting model parameters to fit certain equation-sets (Ion et al 1986; Barbosa et al 1988); and development of a new material model for precipitation-hardened materials that is based on a hyperbolic sine stress function (Dyson 1994).

A hyperbolic sine stress function rationalises the stress dependent ' $n$ ' values widely reported in the literature on precipitation-hardened engineering alloys. In addition, the new theory has suggested a totally different interaction between particle-coarsening and strain rate which has been validated using creep data obtained on virgin and aged 1Cr1/2Mo steel (Dyson \& Osgerby 1993). Table 1 summarises the state-of-the art for single damage CDM models using the hyperbolic sine formulation.

In the light of the above brief review of the status of CDM, the next section presents some new information on creep modelling in the presence of damage due to interaction with oxygen in the surrounding environment.

\section{Modelling of creep/oxygen-environment attack}

Exposure of pure metals or solid solution alloys to air during creep often results in lower creep rates and longer lives compared to data obtained in vacuum. The reason is simply due to the higher creep strength and greater volume of the surface oxide and is facilitated by a combination of a weak alloy with a fast-growing oxide. In contrast, ferritic steels and nickel base superalloys often display creep lifetimes in air that are often much shorter than in vacuum or inert atmosphere. Two quite different micromechanisms have been identified as being responsible: (i) in low-alloy ferritic steels, oxides have been observed to spall, reducing the load-bearing section and accelerating creep (Cane \& Manning 1981); (ii) in nickel-base superalloys, oxygen penetrates into the material during heat treatment and creates a surface zone of grain boundary cavitation which manifests itself in much reduced ductilities and lifetimes during subsequent creep at lower temperatures (Pandey et al 1984).

\subsection{Modelling damage due to oxygen penetration}

The mechanism of degradation when oxygen penetrates into a nickel-base material at high temperatures is believed to be carbon dioxide bubble formation along grain boundaries. The experiments of Bricknell \& Woodford (1982) demonstrated conclusively that carbon dioxide gas bubbles were formed along grain boundaries of dilute nickel-carbon alloys when exposed to air at temperatures of the order of $1000^{\circ} \mathrm{C}$. Their presence seriously reduced ductilities in subsequent creep at lower temperatures. Much evidence has been accumulated by Bricknell \& Woodford (1982), Pandey et al (1984) and Osgerby \& Dyson (1990a) that points tu a similar effect occurring in nickel- base superalloys: creep ductilities are reduced even more dramatically than in nickelcarbon alloys, but the evidence for a carbon dioxide gas reaction, although strong, 
remains largely circumstantial since bubbles have never been found after heat treatment alone. Carbon monoxide formation has been detected by mass spectroscopy in one system after pre-exposure and creep (Pandey et al 1992).

One of the major findings of Pandey et al (1984) that under certain conditions (higher temperatures), oxygen is able to penetrate into the material more easily under reduced oxygen potentials, has now been substantiated by other investigations (Pandey et al 1986; Osgerby \& Dyson 1990b). This finding has focussed attention on the need for a better understanding of the kinetics of carbon dioxide formation in addition to the kinetics of formation of barrier oxides such as alumina and chromia. CDM also requires a quantitative damage evolution rate which necessitates better knowledge of the kinetics of formation of both $\mathrm{CO}_{2}$ gas bubbles and oxide scales under reduced pressure. Kinetic data on carbon dioxide gas bubble formation are sparse but lacocca $\&$ Woodford (1988) report an activation energy for the rate of advance of the bubble interface that is close to the volume self diffusion coefficient in nickel, $D_{v}$. Oxygen diffuses interstitially in nickel with an activation energy approximately 0.6 that of $D_{v}$ (Park \& Alstetter 1988); the implication must be therefore that more than one activation process is important in determining the rate of advance of the reaction-front. The next section proposes a kinetic model for $\mathrm{CO}_{2}$ gas bubble formation and exemplifies its potential using data from a nickel-carbon alloy.

3.1a New kinetic model for $\mathrm{CO}_{2}$ gas bubble formation: Consider figure 1 which illustrates the planar concentration profile of dissolved oxygen in nickel containinga surface film of $\mathrm{NiO}$ that maintains a concentration $C_{[0]}^{\prime}$ for all time, $t$. The reactionfront occurs at a distance $d$ below the surface at an oxygen concentration of $C_{[0], R}$. If the diffusivity of oxygen in nickel, $D_{[\mathrm{O}]}$, is reasonably assumed to be independent of distance $x$, then the oxygen profile as a function of $x$ and $t$ is given in standard treatments (Crank 1956) as

$$
C_{[0]}=C_{[O]}^{\prime} \operatorname{erfc}\left(x / 2\left(D_{[0]} t\right)^{1 / 2}\right)
$$

and therefore

$$
C_{[\mathrm{O}], R}=C_{[\mathrm{O}]}^{\prime} \operatorname{erfc}\left[d / 2\left(D_{[\mathrm{O}]} t\right)^{1 / 2}\right] .
$$

When the ratio $C_{[\mathrm{O}], R} / C_{[\mathrm{O}]}^{\prime}$ is independent of temperature, then $D_{[\mathrm{O}]} \propto d^{2} / t$ and

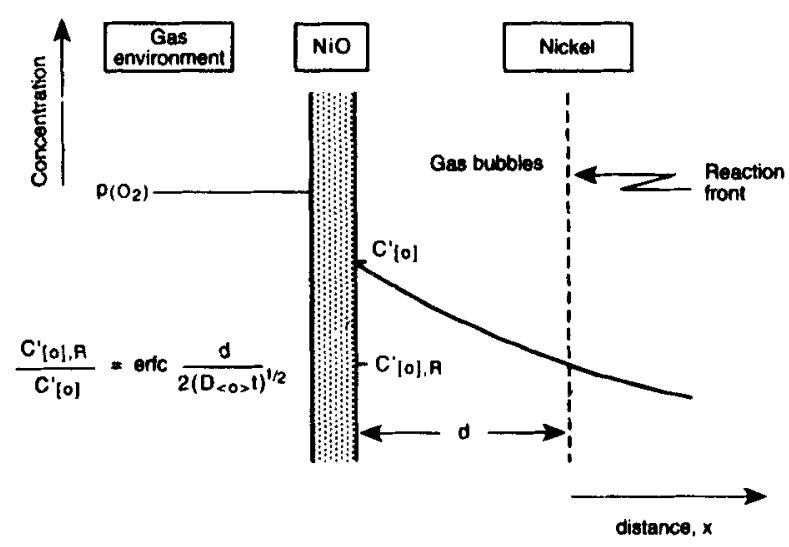

Figure 1. Schematic representation of the oxygen diffusion profile in nickel ahead of a surface layer of $\mathrm{NiO}$. 
the activation energy of the reaction-front kinetics becomes equal to that for diffusion. This will not be true in general since $C_{[0] . R}$ and $C_{[0]}^{\prime}$ are both functions of temperature.

$C_{[\mathrm{O}]}^{\prime}$ is maintained at a level proportional to the square root of the dissociation pressure $P_{\left(\mathrm{O}_{2}\right)}$ of $\mathrm{NiO}$ and is given by

$$
C_{[\mathrm{O}]}^{\prime}=K(T) \exp \left[\Delta \mu_{\langle\mathrm{NiO}\rangle}^{0} / R T\right],
$$

where $K(T)$ is the equilibrium constant for solution of oxygen in nickel and $\Delta \mu_{\langle\mathrm{NiO}\rangle}^{0}$ is the standard free energy of formation of $\mathrm{NiO}$.

The nucleation condition for $\mathrm{CO}_{2}$ bubble formation is reached when $P_{1 \mathrm{CO}_{2} \mathrm{~h}}=2 \gamma / r_{c}=P^{*}$, where $\gamma$ is the surface tension and $r_{c}$ the critical bubble radius. Consideration of the $\mathrm{CO}_{2}$ reaction kinetics at the bubble/matrix interface, gives:

$$
C_{[0] \cdot R}=K(T)\left[P^{*} / a_{[\varepsilon]}\right]^{1 / 2} \exp \left[\Delta \mu_{\left(\mathrm{CO}_{2}\right)}^{0} / 2 R T\right]
$$

where $a_{[c]}$ is activity of carbon in nickel and $\Delta \mu_{\left(\mathrm{CO}_{2}\right)}^{0}$ is the standard free energy of formation of $\mathrm{CO}_{2}$.

The ratio $C_{[0], R} / C_{[0]}^{\prime}$ can now be calculated using (7)-(9)

$$
\frac{C_{[\mathrm{O}], R}}{C_{[\mathrm{O}]}^{\prime}}=\left[\frac{P^{*}}{a_{[c]}}\right]^{1 / 4} \exp \left[\frac{\Delta \mu_{\left(\mathrm{CO}_{2}\right)}^{0}-2 \Delta \mu_{(\mathrm{NiO})}^{0}}{2 R T}\right]=\operatorname{erfc}\left[\frac{\mathrm{d}}{2\left(D_{[\mathrm{O}]} t\right)^{1 / 2}}\right] .
$$

3.1b Application to a nickel-carbon alloy: Kubaschewski \& Alcock (1979) have tabulated equations for $\Delta \mu_{\left(\mathrm{CO}_{2}\right)}^{0}$ and $\Delta \mu_{(\mathrm{NiO})}^{0}$ :

$$
\begin{aligned}
& \Delta \mu_{\left(\mathrm{CO}_{2 \mathrm{t}}\right.}^{0}=-\left[3.96 \times 10^{5}+0.84 T\right] \mathrm{J} \mathrm{mol}^{-1}, \\
& \Delta \mu_{\langle\mathrm{NiO}\rangle}^{0}=-\left[2.35 \times 10^{5}-85.6 T\right] \mathrm{J} \mathrm{mol}^{-1} .
\end{aligned}
$$

Substituting into (10) gives

$$
\operatorname{erfc}\left[d / 2\left(D_{[0]} t\right)^{1 / 2}\right]=3.55 \times 10^{-5}\left[P^{*} / a_{[c]}\right]^{1 / 2} \exp (4450 / T)
$$

The activity coefficient for carbon in nickel, $\gamma_{c^{\prime}}$ has been derived previously (Dyson 1982):

$$
\gamma_{c}=2 \exp [4763 / T]
$$

Substituting (12) into (11) gives

$$
\operatorname{erfc}\left[d / 2\left(D_{[0]} t\right)^{1 / 2}\right]=2.5 \times 10^{-5}\left[P^{*} / C_{[C]}\right]^{1 / 2} \exp (2069 / T) .
$$

where $C_{[\mathrm{C}]}$ is the atom fraction of carbon in nickel.

Homogeneous nucleation of carbon dioxide gas bubbles in nickel requires pressures of the order of $10^{5}$ atmospheres and is an unlikely event (Dyson 1982). We will assume $P^{*}$ to be one tenth of this value, implying heterogeneous nucleation at sites having defects a few nanometres in radius. This is consistent with gas bubbles lying only along grain boundaries. Substituting for $P^{*}$ in (13) gives

$$
\operatorname{erfc}\left[d / 2\left(D_{[\mathrm{OO}]} t\right)^{1 / 2}\right]=2.5 \times 10^{-3}\left[C_{[\mathrm{c}]}\right]^{-1 / 2} \exp (2069 / T)
$$

The experiments of Iacocca \& Woodford (1988) used an alloy containing $135 \mathrm{ppm}$ of carbon by weight, i.e. $C_{[\mathrm{Cl}}=6.6 \times 10^{-4}$. Thus, from (14),

$$
\operatorname{erfc}\left[d / 2\left(D_{[0]} t\right)^{1 / 2}\right]=9 \cdot 8 \times 10^{-2} \exp (2069 / T) .
$$


In order to derive an apparent activation energy, values of the parameter $d^{2} / t$ were calculated as a function of temperature using tables of the Error Function Complement and the equation for $D_{[0]}$ given by Park \& Alstetter (1988)

$$
D_{[0]}=4.9 \times 10^{-6} \exp (-19700 / T) \text {. }
$$

Values of $d^{2} / t$ are plotted against $1 / T$ in the conventional manner in figure 2, from which an activation energy of $211 \mathrm{~kJ} \mathrm{~mol}^{-1}$ can be derived. This activation energy is substantially greater than the diffusion activation energy of $163.8 \mathrm{~kJ} \mathrm{~mol}^{-1}$ input through (11). Figure 2 demonstrates that the frequently used practice of deducing activation energies for oxygen diffusion from measurements on reaction-front kinetics can be very misleading.

It has often been assumed (Bricknell \& Woodford 1982; Iacocca \& Woodford 1988) that oxygen diffuses faster down grain boundaries and so gives rise to the $\mathrm{CO}_{2}$ gas bubbles found preferentially along grain boundaries. However, even a cursory inspection of the rates of transport of substitutional solutes through grains relative to those along grain boundaries indicates that at these high temperatures (greater than $0 \cdot 7 T_{m}$ ), most of the flux will be transported through the grains. Dyson \& Hondros (1985) demonstrated this quantitatively and also pointed out that even when grain boundary transport is dominant, reaction-front kinetics will obey a $t^{1 / 4}$ law with a low activation energy and not the $t^{1 / 2}$ law with a high activation energy observed experimentally for $\mathrm{CO}_{2}$ bubble formation. A further piece of evidence favouring mass transport of oxygen through the grain interiors is shown in figure 3, which compares the tracer volume diffusion data of nickel in a Ni-20\% Cr alloy (Frost \& Ashby 1982) with the relatively recent data of oxygen in nickel by Park \& Alstetter (1988). The less complete and older data of Kerr (1972) are also included in figure 3. It is clear that oxygen diffusivities are considerably greater than tracer nickel diffusivities and that oxygen diffuses with a lower activation energy. Thus oxygen almost certainly diffuses interstitially in nickel

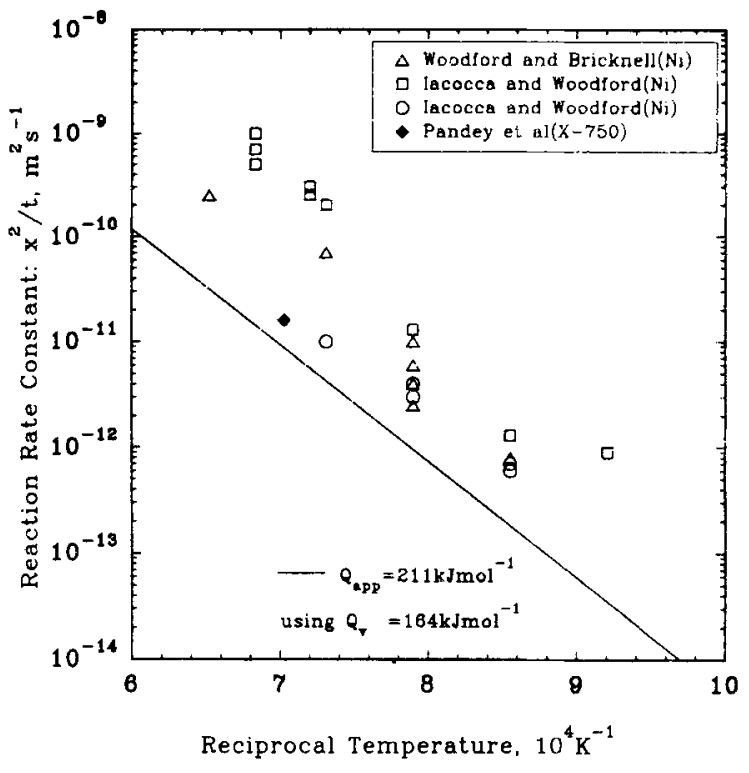

Figure 2. Comparison of predicted reaction-rate constant for $\mathrm{CO}_{2}$ bubble formation (solid line giving an activation energy of $211 \mathrm{~kJ} \mathrm{~mol}^{-1}$ ) with experimental data. 


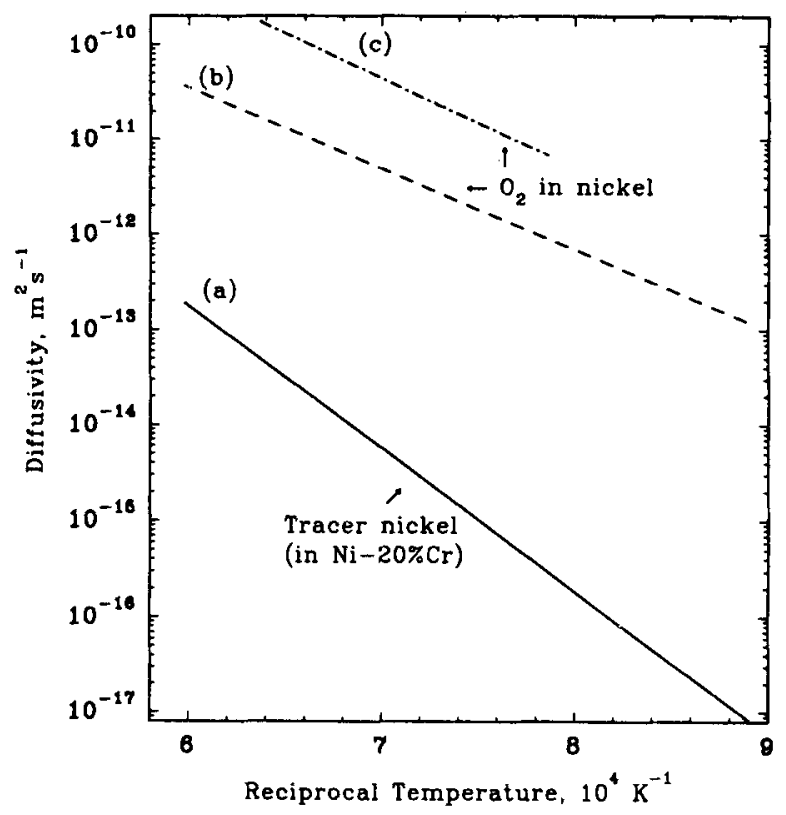

Figure 3. Comparison of experimental diffusivities of tracer $\mathrm{Ni}$ in a nickel-chromium alloy with two sets of measurements of oxygen diffusion in nickel. (a) Frost \& Ashby (1982), (b) Park \& Alstetter (1988), (c) Kerr (1972).

and will have little or no tendency to diffuse faster along grain boundaries. The reason for the appearance of $\mathrm{CO}_{2}$ bubbles only along grain boundaries cannot therefore be due to rapid transport down the boundaries, as Woodford and co-workers have consistently suggested, but must be a consequence of preferential nucleation. This is consistent with the assumption of a constant $\mathrm{CO}_{2}$ pressure term, $P^{*}$, in $\S 3 \cdot 1 \mathrm{a}$.

The model predictions of $d^{2} / t$ can be compared in figure 2 with the $\mathrm{CO}_{2}$ penetration rate data of Woodford and co-workers on nickel and the single datum point of Pandey et al (1986) on the nickel superalloy X-750. The model predictions fall slightly below the lower limit of the experimental dataset but the agreement must be considered satisfactory considering the indpendent data input to the model and the large experimental scatter (due in part to the use of cylindrical section thicknesses which, according to Iacocca $\&$ Woodford (1988), were too small relative to the diffusion distance and so overestimated $d^{2} / t$ because of an assumed infinite plane slab of material in their analysis). Better agreement with the dataset could have been achieved using the (poorer pedigree) oxygen diffusivity data of Kerr (1972).

3.1c Incorporation into the CDM framework: During creep, the presence of a subsurface layer containing cavity nuclei implies pre-existing damage in the material. The damage parameter and its effect on creep rate are identical to those given in table 1 under the internal oxidation mechanism; in this particular case of pre-exposure to the environment, the damage accumulation rate is zero. Pandey et al (1986) and Osgerby $\&$ Dyson (1990a) showed that for the wrought Ni-base superalloy, Inconel X-750, the measured creep rate in testpieces exposed to air at $1000^{\circ} \mathrm{C}$ for various times showed good agreement with model predictions of penetration depth when $f$ was assigned a value $=1 / 3$, a value that corresponds to cavitation on every transverse grain boundary in the environmentally damaged region. 


\subsection{Modelling damage due to periodic oxide-spallation}

The equation-set developed to describe uniaxial creep behaviour of low-alloy ferritic steels in the absence of environmental attack (Dyson \& Osgerby 1993) is

$$
\begin{aligned}
\dot{\varepsilon} & =\dot{\varepsilon}_{0} \sinh \left[\sigma(1-H) /\left\{\sigma_{0}(1-S)(1-\omega)\right\}\right], \\
\dot{H} & =\left(h^{\prime} / \sigma\right)\left[1-\left(H / H^{*}\right)\right] \dot{\varepsilon}, \\
\dot{S} & =\left(K^{\prime} / 3\right)(1-S)^{4}, \\
\dot{\omega} & =\left(1 / 3 \varepsilon_{u}\right) \dot{\varepsilon} .
\end{aligned}
$$

Under the usual laboratory conditions of constant load, there is a further constraint on the change of stress with time given by $\dot{\sigma}=\sigma \dot{\varepsilon}$.

The model material parameters $\dot{\varepsilon}_{0}, \sigma_{0}, h^{\prime}, H^{*}, K^{\prime}$ and the uniaxial ductility $\varepsilon_{u}$ are generally functions of temperature, but Dyson \& Osgerby (1993) found that the primary creep parameters $h^{\prime}$ and $H^{*}$ could be regarded as constants without significant change in predicted lifetimes. Two of the model parameters, $\dot{\varepsilon}_{0}$ and $K^{\prime}$, are exponentially related to temperature with activation energies dictated by physics to lie within welldefined narrow bands. The parameter $\sigma_{0}$ is related to the volume fraction and initial dispersion of the particles. The coarsening of the dispersion with time is given by the Greenwood (1956), Wagner (1961) or Lifshitz-Slyozov (1961) expression for particle coarsening, $\dot{S}$, and the variation of particle volume-fraction with temperature is currently accounted for in an empirical way.

Table 2 gives values for the intrinsic (i.e. in the absence of environmental-attack) model material parameters determined for a normalised and tempered $1 \% \mathrm{Cr} 1 / 2 \%$ Mo ferritic steel over the temperature range $530-625^{\circ} \mathrm{C}$ (Dyson \& Osgerby 1993).

Equation-set (17) can be integrated numerically to give lifetimes under a variety of imposed external constraints. Figure 4 is an example under constant load and temperature: two temperature, $550^{\circ} \mathrm{C}$ and $625^{\circ} \mathrm{C}$, are given and at each temperature, lifetimes are predicted both with and (artificially) without the ageing term $\dot{S}$ operating. The importance of particle ageing during the test in curtailing lifetimes, particularly under service conditions, is amply demonstrated in figure 4 : at a typical service stress of $40 \mathrm{MPa}$ at $550^{\circ} \mathrm{C}$, ageing will reduce lifetimes by more than two orders of magnitude.

Environmental-attack by oxygen to create an oxide which then spalls periodically was identified as a problem for remanent lifetime prediction by Cane \& Manning (1981). They pointed out that data obtained in a laboratory on testpieces (approximate diameter $10 \mathrm{~mm}$ ) may give a pessimistic estimate of remanent lifetime of components that are often in excess of $100 \mathrm{~mm}$ in section: testpiece data would fail prematurely due

Table 2. Intrinsic model material parameters for a $1 \mathrm{Cr} 1 / 2 \mathrm{Mo}$ ferritic steel.

\begin{tabular}{lcccc}
\hline$\dot{\varepsilon}$ & $\begin{array}{c}\sigma_{0} \\
\left(h^{-1}\right)\end{array}$ & $\begin{array}{c}h^{\prime} \\
(\mathrm{MPa})\end{array}$ & $H^{*}$ & $\left(h^{-1}\right)$ \\
\hline$\frac{1.4 \times 10^{9}}{\sigma_{0}} \exp -\left[\frac{31000}{T}\right]$ & $8 \times 10^{-3} \exp \left[\frac{6000}{T}\right]$ & $10^{5}$ & 0.4 & $1.4 \times 10^{12} \sigma_{0}^{3} \exp -\left[\frac{36000}{T}\right]$
\end{tabular}




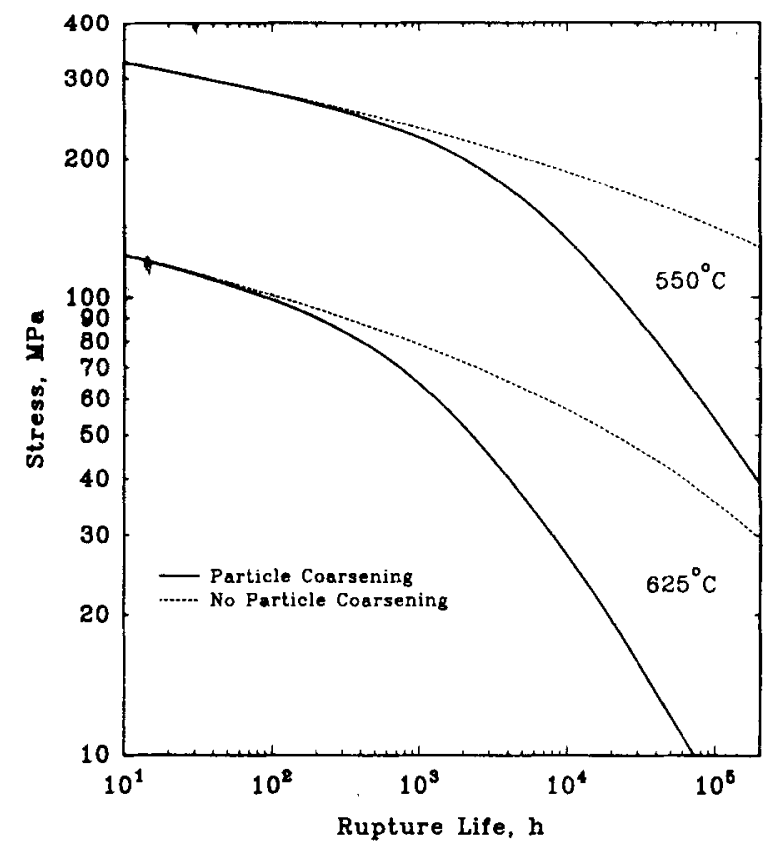

Figure 4. Model predictions of creep lifetime as a function of stress at two temperatures. The solid lines refer to material undergoing particle-ageing and the dashed lines to a hypothetical "non-ageing" material. Model parameters for $1 \mathrm{Cr}$ 1/2Mo steel (Dyson \& Osgerby 1993).

to the greater rate of loss of load-bearing area in $10 \mathrm{~mm}$ section size compared to $100 \mathrm{~mm}$.

Various models have been proposed for the damage rate, $\dot{S}_{c}$, due to this mechanism (Manning 1981; Ashby \& Dyson 1984; Dyson \& Osgerby 1989). It was shown by Dyson \& Osgerby (1989) that these could all be written in the following way:

$$
\dot{S}_{c}=(2 / R) \kappa \dot{\varepsilon}^{\alpha},
$$

where $\alpha$ is either 0.4 or 0.5 and $\kappa$ is a term containing the parabolic rate constant for oxidation, $K_{p} ; \kappa$ is proportional to either $K_{p}^{0 \cdot 5}$ or $K_{p}^{0 \cdot 6}$. Table 1 gives the formalism due to Ashby \& Dyson (1984).

Equation (18) was incorporated into equation-set (17) to assess the effect of spallation on predicted creep lifetimes. The creep strain rate equation becomes

$$
\dot{\varepsilon}=\dot{\varepsilon}_{0} \sinh \left[\sigma(1-H) /\left\{\sigma_{0}(1-S)\left(1-S_{c}\right)(1-\omega)\right\}\right] .
$$

The spalling criterion proposed by Manning (1981) has been used here to give an equation for $\dot{S}_{c}$;

$$
\dot{S}_{c}=\frac{2}{R}\left(\frac{4 E}{15 \gamma_{i}}\right)^{0 \cdot 2} K_{p}^{0 \cdot 6} \dot{\varepsilon}^{0 \cdot 4}
$$

where the oxide modulus $E=200 \mathrm{GPa}$; and the oxide/metal interfacial energy $\gamma_{i}=2 \mathrm{Nm}^{-1} \cdot \gamma_{i}$ could be considerably lower than this and thus represents a lower bound on $\dot{S}_{c}$. However even a ten-fold decrease in $\gamma_{i}$ would result in only a $60 \%$ increase in $\dot{S}_{c}$. A much more sensitive parameter is $K_{p}$. Data for $K_{p}$ as a function of temperature have been reported for a number of low-alloy ferritic steels (Pinder 1977). A mean line 


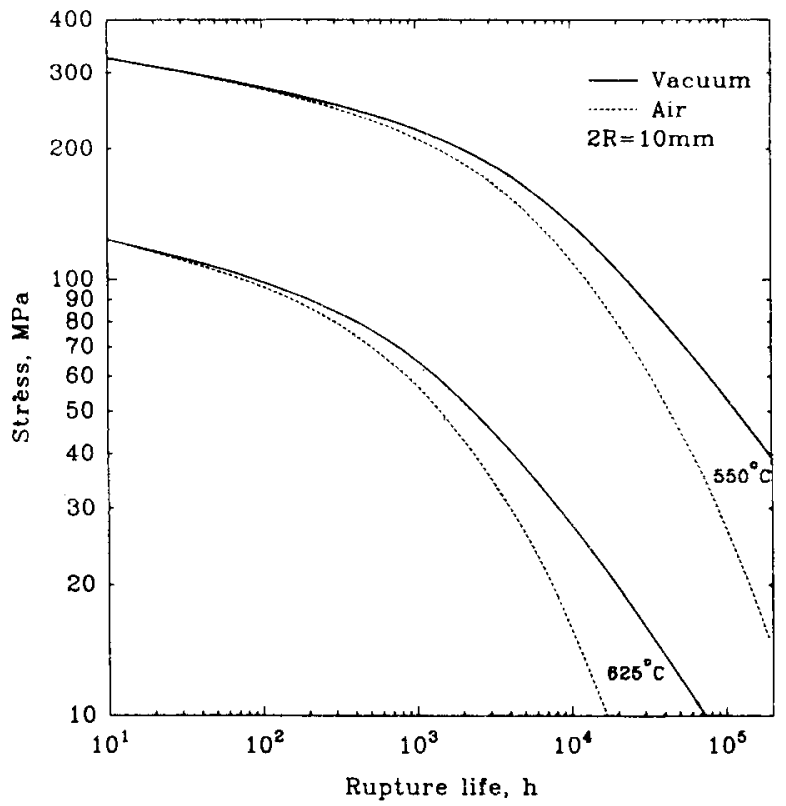

Figure 5. Model predictions of creep lifetime in air and in vacuum as a function of stress at two temperatures. Model parameters for $1 \mathrm{Cr} 1 / 2 \mathrm{Mo}$ steel (Dyson \& Osgerby 1993).

through these data has been calculated for the present work:

$$
K_{p}=7 \cdot 7 \times 10^{-6} \exp -[13000 / T] \mathrm{m}^{2} \mathrm{~h}^{-1} .
$$

Equation (21) applies only to the temperature range $500-625^{\circ} \mathrm{C}$.

Lifetimes were calculated at $550^{\circ} \mathrm{C}$ and $625^{\circ} \mathrm{C}$ using (19)-(21), along with the intrinsic model parameters given in table 2 and assuming a testpiece diameter, $2 \mathrm{R}$,

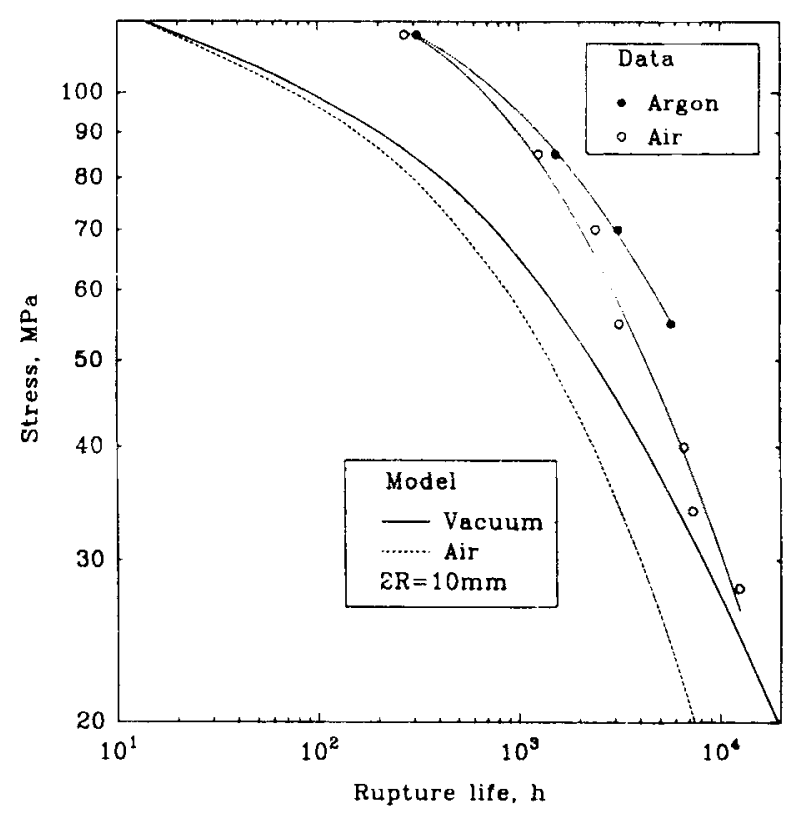

Figure 6. Illustrating that the predicted effect of air exposure on a $1 \mathrm{Cr} 1 / 2 \mathrm{Mostecl}$ at $625^{\circ} \mathrm{C}$ is qualitatively similar to the measured effect on a $1 / 2 \mathrm{Cr}$ $1 / 2 \mathrm{Mo} 1 / 4 \mathrm{~V}$ steel. 
equal to $10 \mathrm{~mm}$ (figure 5). The predictions cannot yet be verified for this alloy since there do not appear to be experimental data in the literature. However, qualitative support for the model is shown in figure 6 which reproduces experimental data in air and argon using a $1 \% \mathrm{Cr} 1 / 2 \% \mathrm{Mo} 1 / 4 \% \mathrm{~V}$ steel (Cane \& Townsend 1985). The important point to note is the similarity in the relative lifetimes between argon and air, since the longer absolute lifetimes of the $\mathrm{CrMoV}$ steel simply reflect its greater intrinsic creep resistance.

\section{Concluding remarks}

Physics-based creep continuum damage mechanics is emerging as a powerful quantitative tool in design and remanent lifetime prediction. Its computer-friendly format makes it ideal for finite element work which will increasingly become less specialised as the ratio of price to computational power continues to fall. This paper has focused on two mechanisms of creep/environmental interaction; there are almost certainly others to identify but the strength of a physics-based approach is that these can be accommodated without prejudicing the conclusions of existing models.

Attack of nickel-base alloys by oxygen diffusing into the metal from the environment and forming $\mathrm{CO}_{2}$ bubbles is now a well-studied phenomenon, but work still needs to be done to validate predictions of the CDM model, particularly in extending the temperature/ time range of applicability of the damage-rate kinetics. The paper has made some progress particularly with regard to defusing the idea prevalent in the literature that the process is controlled by oxygen diffusion along grain boundaries. A kinetic model utilising oxygen diffusion within the matrix has been proposed which can account satisfactorily for the large experimental dataset on this subject.

The authors would like to thank Dr M C Pandey (Defence Metallurgical Research Lab, Hyderabad) for general discussions and for bringing to their attention the papers by Iacocca \& Woodford (1988) and Park \& Alstetter (1988).

\section{List of symbols}

A dot over any symbol signifies the derivative with respect to time

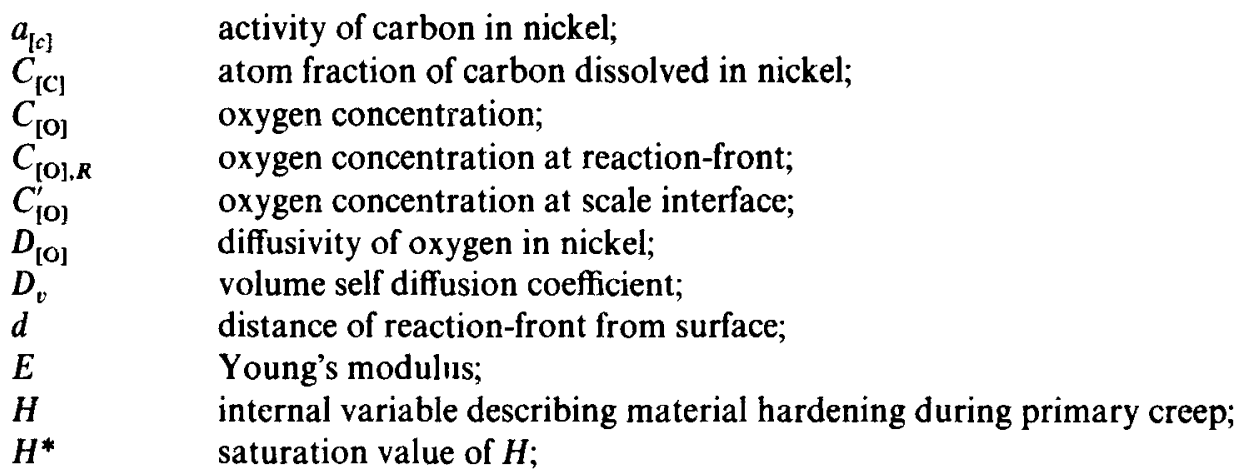


$h^{\prime} \quad$ coefficient for material hardening during primary creep;

$K^{\prime} \quad$ coefficient for material softening due to precipitate coarsening;

$K_{p} \quad$ parabolic rate constant for oxidation:

$K(T) \quad$ equilibrium constant for solution of oxygen in nickel;

$n$

$P_{\left(\mathrm{CO}_{2}\right)}$

$P_{\left(\mathrm{O}_{2}\right)}$

$P^{*}$

$R$

stress exponent for power law creep;

pressure of carbon dioxide in bubble;

dissociation pressure of nickel oxide;

critical pressure for nucleation of carbon dioxide gas bubbles;

radius of cylindrical testpiece;

critical radius for gas bubble;

$r_{c}$

$S$

$S_{c}$

$T$

$t$

$\alpha$

$\gamma_{i}$

$\varepsilon$

$\varepsilon_{0}$

$\varepsilon_{\mathrm{u}}$

$\kappa$

$\Delta \mu_{(\mathrm{NiO})}^{0}$

$\Delta \mu_{\left(\mathrm{CO}_{2}\right)}^{\mathrm{o}}$

internal variable describing material softening;

internal variable describing material softening due to corrosion;

temperature;

time;

exponent for damage due to oxide scale spallation;

surface tension;

oxide/metal interfacial energy;

creep strain rate;

material parameter in sinh law;

uniaxial creep ductility;

coefficient for damage due to oxide scale spallation;

standard free energy of formation for nickel oxide;

standard free energy of formation for carbon dioxide;

applied uniaxial stress;

material strength parameter in sinh law;

$\sigma_{0}$

$\omega$

internal variable describing material softening and fracture due to creep cavitation.

\section{References}

Ashby M F, Dyson B F 1984 Creep damage mechanics and micromechanisms. In Advances in fracture research (eds) S R Valluri et al (Oxford: Pergamon) pp. 3-30

Barbosa A, Taylor N G, Ashby M F, Dyson B F, McLean M 1988 A model- based computer analysis of creep data (CRISPEN)-applications to nickel-base superalloys. In Superalloys 88 (eds) D N Dahl et al (Warrendale, PA: The Metallurgical Society) pp. 683-692

Bricknell R H, Woodford D A 1982 The mechanism of cavity formation during high temperature oxidation of nickel. Actu Metall 30: 257 264

Cane B J, Manning M I 1981 Effect of testpiece oxidation on rupture data. CERL Note LM/MATS $/ 407$

Cane B J, Townsend R D 1985 Prediction of remaining life in low-alloy steels. Flow and fracture at elevated temperatures (Ohio: ASM) pp. 279-316

Dyson B F 1982 Analysis of carbon/oxygen gas bubble formation in some nickel alloys. Acta Metall. 30: $1639 \cdots 1646$

Dyson B F. Gibbons T B 1987 Tertiary creep in nickel-base superalloys: analysis of experimental data and theoretical synthesis. Acta Metall. 35: 2355-2369

Dyson B F, Hondros E D 1985 Chemical environment effects on creep fracture. Advances in fracture research (eds) S R Valluri et al (Oxford: Pergamon) pp. 3753-3772

Dyson B F, Osgerby S 1989 Modelling synergy between creep and corrosion for ergineering design. In Materials for engineering design: The next decade (eds) B F Dyson, D R Hayhurst (London: Institute of Metals) pp. $373-379$ 
Frost H J, Ashby M F 1982 Deformation mechanism maps: the plasticity and creep of metals and ceramics (Oxford: Pergamon)

Greenwood G W 1956 The growth of dispersed precipitates in solution Acta Metall. 4: 243-248

lacocca R G, Woodford D A 1988 The growth of dispersed precipitates in nickel and its relevance to weldment cracking. Metall. Trans. A A19: 2305-2313

Ion J, Barbosa A, Ashby M F, Dyson B F, McLean M 1986 The modelling of creep for engineering design - I. NPL Report, DMA (A) 115

Kerr R A 1972 M S Thesis, Ohio State University, Columbus, Ohio

Kubaschewski O, Alcock C B 1979 Metallurgical thermochemistry 5th edn (Oxford: Pergamon)

Liftshitz J M, Slyozov V V 1961 The kinetics of precipitation from supersaturated solid solutions. J. Phys. Chem. Solids 19: 35-50

Manning M I 1981 Corrosion and mechanical stress at high temperature (eds) V Guttman, W Merz (London: Applied Science) pp. 323-338

Osgerby S, Dyson B F 1990a Effects of oxygen on creep performance: Mechanisms and predictive modelling. Mater. Sci. Technol. 6:2-8

Osgerby S, Dyson B F 1990b Environmental embrittlement of superalloys during coating processes. In Surface engineering practice; Processes, fundamentals and applications (eds) K N Strafford, P K Datta, J S Gray (Chichester: Ellis Horwood) pp. 466--474

Othman A M, Hayhurst D R, Dyson B F 1993 Skeletal point stresses in circumferentially notched tension bars undergoing tertiary creep modelled with physically-based constitutive equations. Proc. $R$. Soc. London A441: 343-358

Pandey M C, Dyson B F, Taplin D M R 1984 Environmental, stress-state and section size synergisms during creep. Proc. $R$. Soc. London A393: 117-131

Pandey M C, Taplin D M R, Ashby M F, Dyson B F 1986 The effect of prior exposure time on air-environment/creep interactions. Acta Metall. 34: 2225-2233

Pandey M C, Satyanarayana D V V, Rama Rao P 1992 An analysis of the creep-environment interaction of Inconel alloy X-750. Mater High Temp. 9: 167-173

Park J W, Alstetter C J 1988 The diffusion and solubility of oxygen in solid nickel. Metall. Trans. A18: 43-50

Pinder L W 1977 Oxidation kinetics and scale morphology of mild steel and low chromium alloy stels in $\mathrm{N}_{2} / 20 \% \mathrm{O}_{2}$ between 500 and 850 C. CEGB Report, SSD/MID/R58/77

Wagner $C 1961$ Theory of the ageing of precipitates by redissolution (Ostwald maturing). Elektrochem. 65: 581-591

Woodford D A, Bricknell R H 1986 Embrittlement of high temperature alloys. Treatise on materials science and technology. Embrittlement of engineering alloys (London: Academic Press) vol, 25, pp. 157-199 